\title{
A Corpus Based Approach to the Analysis of Structures in Prepositional Phrase
}

\author{
Ni Wayan Swarniti \\ Faculty of Teacher Training and Pedagogy, Dwijendra University \\ wayanswarniti@undwi.ac.id
}

\begin{abstract}
The written text can not be separated from using prepositional phrase, because prepositional phrase makes a sentence complete grammatically. In this research, there was an aim that has to be achieved. Namely: to determine the structures of prepositional phrase. This research was descriptive qualitative-quantitative research. The data sources of this research were taken from phrases that have prepositional phrase in 50 articles of law. In this research, corpus linguistic was used as the method of collecting data. Corpus linguistic used an application in computer. It was AntConc3.2.4w2011. The results of the analysis were presented by using formal and informal technique. The structures of prepositional phrase found were 4 structures. They are prep + det + noun, prep + det + adj + noun, prep + noun, and prep + adj + noun. These structures were found based on some words as triggers in the software of corpus linguistics. Namely: down the, up the, around the, into the, with the, within the, through, in spite of, instead of, in the, at the and out of.
\end{abstract}

Keywords: prepositional phrase; corpus linguistics; grammar

\section{Introduction}

In every written text in English, it is need to concern in the cohesion, generic structure, grammar, and good word choices. Grammar is one of the language components that should be mastered by the students in order to develop accuracy and creativity in using the language in communication (Sudarmawan et al., 2020). It will make the text good and easy to read. Not just about the paragraphs, it is also about every sentence used in a paragraph. Every sentence in each paragraph need to support the main idea of that paragraph.

The written text can not be separated from using prepositional phrase, because prepositional phrase makes a sentence complete grammatically. The structure and the functions of prepositional phrase is very interesting to analyze. As we know the structure of prepositional phrase is prep + det + noun. In this article, the discussion about structure of prepositional phrase was being more specific.

In prepositional phrase, preposition in can be combined with prepositional complement which can make prepositional phrase. A prepositional phrase consists of a preposition followed by prepositional complement, which is characteristically a noun phrase or a WH clause or V-ing clause (Quirk, R. And Greendbaum, 1973).

For example :

There are two beds in the cottage (Quirk, R. And Greendbaum, 1973).

In the example above, preposition phrase in the cottage has a 
structure prep + det + noun. In this sentence, preposition in explains the position of two beds are in the cottage.

The topic of preposition "by" has been written by Abdul Haris (2012) in his book entitled Preposition "by" and Its Translation In Indonesian (Haris, 2012). Now this article analyzed about the topic of the structures of prepositional phrase. The research of Abdul Haris has inspired the writer to make this research. Abdul Haris analyzed the preposition 'by' then the structures of prepositional phrase were analyzed in this research. It was caused the structures of prepositional phrase are very important in making sentence complete grammatically.

The development of modern linguistics is graced with emergence a relatively "new" branch of science, namely corpus linguistics. This science is specifically examines language through a set of data that is natural, real according to its use, both written data and oral data which is transcribed (Adolphs, 2006). According to the definition, a corpus is a collection of data, both ordinary data and digital data, in written form containing various kinds of linguistic information, starting from the level of words, structures, meanings, and discourses, which can be used for research (Hizbullah et al., 2016). Corpus-based study methods have proven established in linguistic research and have expanded most of its methods and language analysis techniques to other disciplines such as lexicology, terminology, language teaching and translation (Candel-mora \& Vargas- sierra, 2013). Advances in information technology and computers can synergize with science linguistic or linguistic so can assist linguistic research more extensively (Gvarishvili, 2013).

Based on the explanation above, this research focused on the discussion of the structures of prepositional phrase in 50 articles of law found in international journal. Hopefully, this research can be the one of knowledge sources related in the uses of prepositional phrase in making sentence complete grammatically. The point that was discussed in this research involve: what are the structures of prepositional phrase found in 50 articles of law. In this research, there was an aim that has to be achieved. Namely: to determine the structures of prepositional phrase. It aims to find the gaps, strength, and weakness. It is helpful for this research to fill in the gaps and to be a different research (Swarniti, 2019).

\section{Method of Research}

This research was descriptive qualitative-quantitative research. The data sources of this research were taken from phrases that have prepositional phrase in 50 articles of law. In this research, corpus linguistic was used as the method of collecting data. Corpus linguistics is an empirical method of analysis and linguistic descriptions to examine the language spoken by speakers naturally (Cheng, 2012). Corpus linguistic used an application in computer. It was AntConc3.2.4w2011. When using the software of corpus linguistic, it was 
needed to use some words as triggers in the application. Those were preposition, such as down the, up the, in the, and out of. After the data were collecting by using the software of corpus linguistic, the data were moved to Microsoft excel to analyze easily. By using Microsoft excel, the data were classified based on their structures of prepositional phrase. The results of the analysis were presented by using formal and informal technique. Formal technique explained by using table for describing in general. Informal technique was used to describe the explanation of results in detail by using sentences.

\section{Finding and Discussion}

Based on the topic discussed, there are some structures of prepositional phrase which were found in the data sources. All of the data in this research were taken from the sentences that has prepositional phrase in 50 articles of law found in international journals. Based on the data sources, the words found that indicate prepositional phrases are 6076 words. It was seen that in the table below:

\begin{tabular}{|c|c|c|c|}
\hline No & Source & $\begin{array}{c}\text { Number of } \\
\text { articles }\end{array}$ & $\begin{array}{c}\text { Number of } \\
\text { words }\end{array}$ \\
\hline 1 & Article of Law & 50 & 6076 \\
\hline
\end{tabular}

Table 1.1

Some of words that found in the data sources were 12 words. Namely: down the, up the, around the, into the, with the, within the, through, in spite of, instead of, in the, at the and out of. Prepositional phrases that followed by those words have 4 structures. They were prep + det + noun, prep + det + adj + noun, prep + noun and prep + adj + noun. It was seen in the following table:

\begin{tabular}{|c|l|c|c|c|c|c|}
\hline \multirow{2}{*}{$\begin{array}{c}\text { N } \\
\text { o }\end{array}$} & \multirow{2}{*}{ Words } & Number & \multicolumn{4}{|c|}{ Structures } \\
\cline { 4 - 7 } & of Words & $\begin{array}{c}\text { Prep + det } \\
+ \text { noun }\end{array}$ & $\begin{array}{c}\text { Prep + det } \\
+ \text { adj }+ \\
\text { noun }\end{array}$ & $\begin{array}{c}\text { Prep + } \\
\text { noun }\end{array}$ & $\begin{array}{c}\text { Prep + adj } \\
\text { + noun }\end{array}$ \\
\hline 1 & Down the & 19 & 15 & 4 & & \\
\hline 2 & Up the & 19 & 17 & 6 & & \\
\hline 3 & Around the & 38 & 34 & 4 & & \\
\hline 4 & Into the & 131 & 104 & 27 & & \\
\hline 5 & With the & 877 & 701 & 176 & & \\
\hline 6 & Within the & 259 & 246 & 13 & & \\
\hline 7 & Through & 138 & 121 & 17 & & \\
\hline 8 & In spite of & 5 & 1 & & 4 & \\
\hline 9 & Instead of & 54 & 4 & & 37 & \\
\hline 10 & In the & 3782 & 3760 & 22 & & \\
\hline
\end{tabular}




\begin{tabular}{|l|l|c|c|c|c|c|}
\hline 11 & At the & 645 & 582 & 63 & & \\
\hline 12 & Out of & 109 & 33 & & 76 & \\
\hline
\end{tabular}

Table 1.2

The analysis in this research is based on the structures of prepositional phrases found. Some examples of the data found will be analyzed specifically.

1. Prep + det + noun

may lead to numerical instabilities compared with the observer.

(Adaptive Reaching Law Based Three-dimensional.txt)

The analysis

with the observer
prep det noun

Based on this example, prepositional phrase with the observer has structure prep + det + noun. The word with expresses preposition. The is as determinant. Observer here is as a noun. This data was found in law journal article entitled Adaptive Reaching Law Based Threedimensional.txt.

2. Prep $+\operatorname{det}+$ adj + noun

the velocity gradient $L$ is decomposed additively into the elastic part Le and plastic part Lp due to

(Finite element multi-impact simulations using a crystal plasticity law based on dislocation dynamics.txt)

The analysis

Into the elastic part

Prep det adj noun

Based on this example, prepositional phrase into the elastic part has structure prep + det + adj + noun. The word into expresses preposition. The is as determinant. The words elastic has function as adjective. Part here is as a noun. This data was found in law journal article entitled Finite element multi-impact simulations using a crystal plasticity law based on dislocation dynamics.txt.

\section{Prep + noun}

end consumer goods ... that have virtually gone out of production in the United States by now and where

(Are Consumer-Oriented Rules the New Frontier of Trade Liberalization.txt).

The analysis

$\begin{array}{ll}\text { Out of } & \text { production } \\ \text { Prep } & \text { noun }\end{array}$

Based on the example above, prepositional phrase out of production has structure prep + noun. The words out of expresses preposition. Production here is as a noun. This data was found in law journal article entitled Are Consumer-Oriented Rules the New Frontier of Trade Liberalization.txt.

4. Prep + adj + noun

This indicates $\backslash$ that, instead of long-term aver $\backslash$ ages such as the $Q$ values, subjects

(Applying the matching law as micro-foundation of.txt)

The analysis

$$
\begin{array}{lll}
\text { Instead of } & \text { long } & \text { term } \\
\text { Prep } & \text { adj } & \text { noun }
\end{array}
$$

Based on the example above, prepositional phrase instead of long- 
term has structure prep + adj + noun. The words instead of expresses preposition. Long here means adjective. Term is as a noun. This data was found in law journal article entitled Applying the matching law as micro-foundation of.txt.

\section{Conclusion}

After analyzing some data before, the conclusion was made. All the structures of prepositional phrase in 50 articles of law have analyzed. The structures of prepositional phrase found were 4 structures. They are prep + det + noun, prep + det + adj + noun, prep + noun, and prep + adj + noun. These structures were found based on some words as triggers in the software of corpus linguistics. Namely: down the, up the, around the, into the, with the, within the, through, in spite of, instead of, in the, at the and out of.

\section{References::}

Adolphs, S. (2006). Introducing Electronic Text Analysis - A Practical Guide for Language and Literary Studies. Routledge.

Candel-mora, M. A., \& Vargas-sierra, C. (2013). An Analysis of Research Production in Corpus Linguistics Applied to Translation. Procedia Social and Behavioral Sciences, 95, 317-324.

https://doi.org/10.1016/j.sbspro.20 13.10.653

Cheng, W. (2012). Exploring Corpus Linguistics: Language in Action. Routledge.

Gvarishvili, Z. (2013). Interference of L1 Prepositional Knowledge in Acquiring of Prepositional Usage in English. Procedia - Social and Behavioral Sciences, 70, 1565-1573. https://doi.org/10.1016/j.sbspro.20 13.01.224

Haris, A. (2012). Prepositional phrase "by" And Its Translation In Indonesian. Warmadewa University.

Hizbullah, N., Rachman, F., \& Fauziah, F. (2016). Linguistik korpus dalam kajian dan pembelajaran bahasa Arab di Indonesia. Konferensi Nasional Bahasa Arab (KONASBARA) II, 385-393.

Quirk, R. And Greendbaum, S. (1973). A University Grammar of English. Longman Group Ltd.

Sudarmawan, I. P. Y., Swarniti, N. W., \& Susila, I. K. M. (2020). The Mistake BusterTechnique for Sentence. LEJU (Language and Education Journal Undiksha), 3(1), 7-14.

Swarniti, N. W. (2019). The Translation Procedures of Bible Translation. 5(2), 187-196.

https://doi.org/10.22225/jr.5.2.1277 .187-196 